Article

\title{
Self-Powered Fast Brazing of Ti-6Al-4V Using Ni/Al Reactive Multilayer Films
}

\author{
Denzel Bridges ${ }^{1}$, Christopher Rouleau ${ }^{2}$, Zachary Gosser ${ }^{2}$, Cary Smith ${ }^{1}$, Zhili Zhang ${ }^{1}$, \\ Kunlun Hong ${ }^{2}$, Jinquan Cheng ${ }^{3}$, Yoseph Bar-Cohen ${ }^{4}$ and Anming $\mathrm{Hu}^{1, * \text { (D) }}$ \\ 1 Department of Mechanical, Aerospace and Biomedical Engineering, University of Tennessee, \\ 1512 Middle Drive, Knoxville, TN 37996, USA; dbridg10@vols.utk.edu (D.B.); csmit121@vols.utk.edu (C.S.); \\ zzhang24@utk.edu (Z.Z.) \\ 2 Center for Nanophase Material Sciences, Oak Ridge National Laboratory, Oak Ridge, TN 37830, USA; \\ rouleaucm@ornl.gov (C.R.); gosserzq@ornl.gov (Z.G.); hongkq@ornl.gov (K.H.) \\ 3 Composite Solutions and Digital Manufacturing LLC, 3315 S. Waterfront Dr, Chandler, AZ 85248, USA; \\ jinquan.cheng@cs3dm.com \\ 4 Jet Propulsion Laboratory (JPL), California Institute of Technology, M.S. 67-119, 4800 Oak Grove Drive, \\ Pasadena, CA 91109, USA; yoseph.bar-cohen@jpl.nasa.gov \\ * Correspondence: ahu3@utk.edu; Tel.: +1-865-974-5993
}

Received: 26 May 2018; Accepted: 12 June 2018; Published: 15 June 2018

\begin{abstract}
Self-powered brazing of Ti-6Al-4V was performed using Ni/Al reactive multilayer films (RMFs) as self-propagated heat resources. BAlSi- 4 was first coated on Ti-6Al-4V by plasma welding, then alternating layers of $\mathrm{Ni}$ and $\mathrm{Al}$ were successfully deposited on BAlSi-4 up to $32.9 \mu \mathrm{m}$ thick with e-beam deposition. The joint microstructure was investigated and the $\mathrm{AlNi}$ and $\mathrm{Ni}_{5} \mathrm{Al}_{3}$ phases were identified in the RMF. The cause for the two phases was determined to be differences in the diffusivity of $\mathrm{Ni}$ and $\mathrm{Al}$, ultrafast brazing time, and faster cooling at the interface between brazing filler metal and the RMF. The maximum temperature of $683{ }^{\circ} \mathrm{C}$ was reached in the brazed joint, with a total RMF thickness of $135 \mu \mathrm{m}$, which is more than sufficient to melt the BAlSi-4 brazing material. The maximum bonding strength obtained was $10.6 \mathrm{MPa}$, with a self-power brazing procedure conducted in a minute. It is possible to further improve the bonding strength by using more ductile RMFs and/or modifying the bonding interface configuration.
\end{abstract}

Keywords: brazing; reactive bonding; self-powered; titanium; nanolayers; reactive multilayer

\section{Introduction}

In-space manufacturing covers a wide range of manufacturing and joining processes. For example, the Sealing, Seaming, Sterilization, and Separation $\left(S^{4}\right)$ process was developed for potential application for Mars sample return missions [1]. In addition, in-space repair is useful for a wider range of exploration mission capabilities, as well as personnel survival in human operated missions. These potential missions have requirements for an extremely high probability of success for full preservation of samples collected from space missions and for ensuring the safe handling of samples and planetary protection of samples and personnel when returned to Earth for analysis [1]. Brazing is one of the most effective methods of joining structures and supports both $\mathrm{S}^{4}$ and repair procedures, however, in-space manufacturing has several stringent requirements that are not considered for terrestrial manufacturing processes. For instance, brazing, generally, requires high input energy, which is traditionally delivered by large, cumbersome equipment, which have a large energy cost. So, one of the objectives of in-space manufacturing is to minimize the necessary input energy, the weight of components, and the total operating time. Failure to consider these parameters may prohibit application and would limit exploration missions to bodies, such as ocean worlds in the solar system, 
including Europa, Enceladus, Ganymede, Callisto, Ceres, and Pluto, which are, increasingly, a potential target of proposed exploration.

Reactive multilayer films (RMFs) are comprised of alternating layers of materials that can be ignited electrically, thermally, by laser pulse, or mechanical striking, producing an exothermic heat release. The process of RMF-assisted joining has been demonstrated using several types, such as $\mathrm{Ti} / \mathrm{Al}[2,3], \mathrm{Ti} / \mathrm{Ni}$ [4], and $\mathrm{Ni} / \mathrm{Al}[5,6]$ in air, vacuum, and underwater for joining similar dissimilar metals, ceramics, and semiconductors [6,7]. Most RMF joining studies have been performed on solder materials (melting point $\leq 450{ }^{\circ} \mathrm{C}$ ) [8] or using furnace-based joining procedures [9,10]. However, electrically ignited RMF joining for brazing applications $\left(>450^{\circ} \mathrm{C}\right)$ has been seldom explored.

Self-powered brazing is a novel and innovative joining process in which the heat required for joining is generated almost entirely from the energy in the brazing materials and only needs an inconsequentially small trigger to release the energy through an exothermic reaction. Using self-powered brazing via self-propagating reactions of $\mathrm{Ni} / \mathrm{Al} \mathrm{RMFs}$ offers an innovative solution that greatly reduces the significant power requirement for brazing and the weight of equipment transported into space. For this study, we will discuss, herein, the preparation of Ni/Al RMFs join Ti-6Al-4V (Ti64) coated with BAlSi-4 as the brazing filler metal and Ni/Al RMFs as the heat source and demonstrate the potential of this new technique, in addition to discussing the phase transformations associated with the bonding procedure.

\section{Materials and Methods}

\subsection{Plasma Coating and Preparation of RMF}

Ti64 was purchased from McMaster-Carr and cut into pieces that were $3 \mathrm{~mm}$ wide and $30 \mathrm{~mm}$ long. Ti64 pieces were coated with BAlSi-4 by melting a BAlSi-4 strip (liquidus temperature $=582{ }^{\circ} \mathrm{C}$ ), purchased from Prince \& Izant, directly on to Ti64 with a plasma welding torch. The composition of Ti64 and BAlSi-4 (BAl) are included in Table 1. The thickness of BAlSi-4 was grinded down to 80-110 $\mu \mathrm{m}$ to optimize the temperature increase experienced by BAlSi- 4 during the RMF reaction. The BAl-coated Ti64 was polished up to a mirror finish with diamond paste. The surface coating and preparation process takes approximately $15 \mathrm{~min}$ per sample, but, for in-space manufacturing, this processing time is necessary and cost effective. The process can also be easily automated in future studies.

Table 1. Elemental composition of Ti64 and BAlSi-4.

\begin{tabular}{cccccccc}
\hline Material & \multicolumn{7}{c}{ Element Composition (at\%) } \\
\hline \multirow{2}{*}{ Ti64 } & $\mathrm{Ti}$ & $\mathrm{Al}$ & $\mathrm{V}$ & & & & \\
\hline & 90 & 6 & 4 & & & & \\
BAlSi-4 & $\mathrm{Al}$ & $\mathrm{Si}$ & $\mathrm{Cu}$ & $\mathrm{Fe}$ & $\mathrm{Mg}$ & $\mathrm{Mn}$ & $\mathrm{Zn}$ \\
& 86.45 & 12.0 & 0.3 & 0.8 & 0.1 & 0.15 & 0.2 \\
\hline
\end{tabular}

$\mathrm{Ni} / \mathrm{Al}$ bilayers were deposited directly on to BAl-coated Ti64 and polyimide substrates using a modified Varian 3118 electron beam evaporator. The pressure inside the chamber was maintained $<5 \times 10^{-6}$ Torr. Ni/Al RMFs were fabricated using electron beam physical vapor (e-beam) deposition. A direct current power supply (Sorensen DC560-18E) was used to heat the substrate during growth, while a deposition controller (Leybold XTC/2) was utilized for rate (nominally $6.5 \AA / \mathrm{s}$ ) and thickness control. Each Ni layer was $44 \mathrm{~nm}$ and each Al layer was $66 \mathrm{~nm}$. This thickness ratio generates an atomic ratio of $\mathrm{Al} / \mathrm{Ni}$ of 1:1 based on the molar volume of $\mathrm{Al}$ and $\mathrm{Ni}$ [11]. A $60 \mathrm{~nm}$-thick Ti layer was added as the bottom layer to help the film adhere to the BAlSi-4 substrate and $30 \mathrm{~nm}$ Ti interlayers were added intermittently to offset the internal stresses in as-deposited RMFs that cause the film to peel off the substrate or delaminate during deposition [12]. Ti was also chosen because of its compatibility with the $\mathrm{Ni} / \mathrm{Al}$ reaction [13]. $\mathrm{Ni}$ was used as the final layer to mitigate oxidation when exposed to 
air. RMFs were also deposited on polyimide sheets so that the RMFs could be peeled off for SEM and XRD analysis.

\subsection{Brazing}

For brazing, the BAl-coated Ti64 pieces with the RMF were arranged in the configuration shown in Figure 1 with applied pressure and ignited using electrical heating via a $13 \mathrm{~V}$ DC power source (Figure 1a). Electrical heating was supplied by touching the side of the BAl coating with 28-gauge Ni wire until the film reacted (within $3 \mathrm{~s}$ ). The same ignition conditions were used for all RMF thicknesses because, based on the literature search, the ignition conditions affect the reaction initiation, but not the propagation [14]. Pressure was applied to ensure close contact between the RMFs and BAlSi-4. Extra RMFs were peeled off the polyimide substrate and added between the BAlSi-4, in addition to the as-deposited amount to vary thickness. RMF thickness $=66 \mu \mathrm{m}$ was used to test the effect of applied pressure on the bonding strength, then the applied pressure that yielded the highest bonding strength was used to test the effect of RMF thickness on bonding strength. Brazed joints underwent lap shear testing to determine the strength (Figure 1b). The free end of the Ti64 plate was cut short to prevent buckling during lap shear testing. The total brazing procedure can be completed within $1 \mathrm{~min}$ and had negligible cooling time. A microhardness map was obtained using Phase II 900-390 Micro Hardness Tester to test a $300 \mu \mathrm{m} \times 300 \mu \mathrm{m}$ area (each point is $50 \mu \mathrm{m}$ apart).
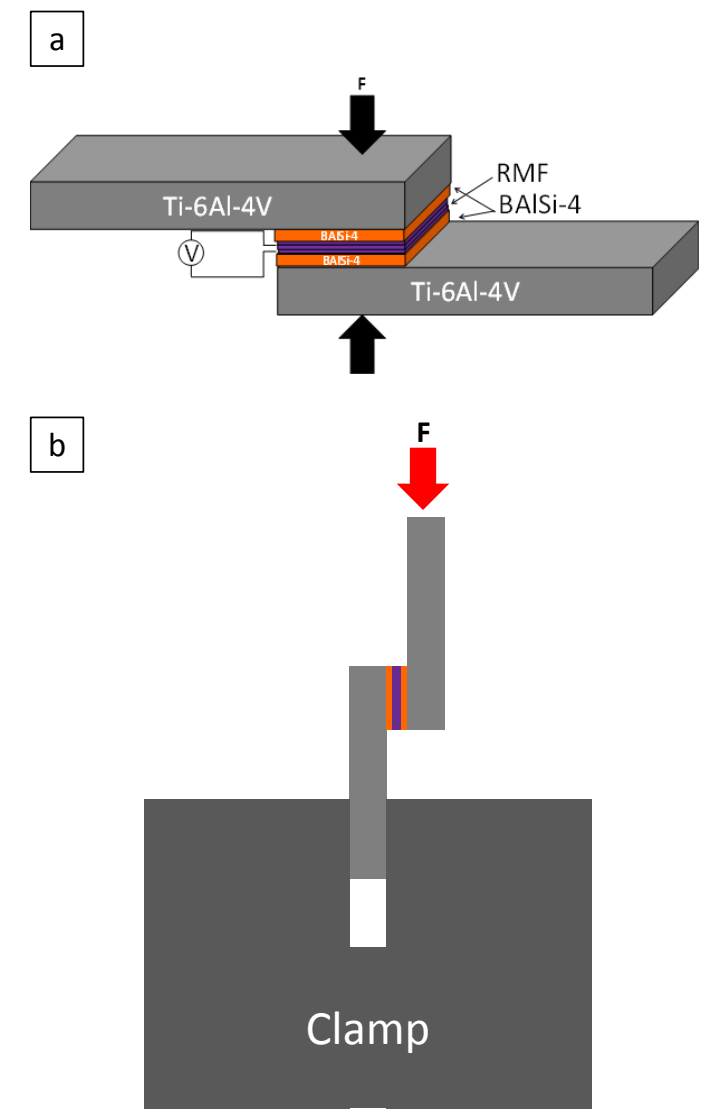

Figure 1. (a) Schematic of the configuration used in brazing experiments. (b) Schematic of lab shear testing.

\subsection{Reaction Temperature Evolution}

The temperature achieved during RMF brazing was estimated computationally and measured experimentally. The temperature was determined computationally using the Layer-wise Additive 
Manufacturing Predictions and Simulations (LAMPS) ${ }^{\odot}$ software (Version 2.0, Composite Solutions and Digital Manufacturing LLC, Chandler, AR, USA, 2017) CS3DM. LAMPS is based on the analytical block technique that enables simulation of moving heat sources, such as the reaction propagation front in RMFs. The model had the parameters shown in Table 2. Thermal conductivity, the coefficient of thermal expansion, and heat capacity are assumed to be constant due to the short timescale of the reaction. It is reasonable for computations on the millisecond scale to assume that the thermophysical properties are temperature independent. Each frame is approximately $50 \mu \mathrm{s}$ and the total simulation time was $3.44 \mathrm{~ms}$. A slice of the cross-section was used for analysis of the temperature during brazing (See Supplementary Materials). The simulation time is shorter than the real reaction and cooldown procedure due to the computational limits of the LAMPS software. To experimentally determine the brazing temperature, a PowerView HS-650 highspeed camera was used to capture several images of BAISi-4 in a furnace heated to a known temperature. The average brightness of the area of interest was extracted using MATLAB (Version R2017b, MathWorks, Natick, MA, USA, 2017) at five temperatures, including room temperature, and derived an equation for the temperature as a function of brightness. The same highspeed camera was used to record the brazing procedure from ignition to reaction extinction. MATLAB was, once again, used to extract the average brightness from the area of interest and, finally, the temperature was calculated using the derived equation. Note that the highspeed camera does not have the same time limitation as the LAMPS simulation, so the temperature of the entire brazing process can be measured.

Table 2. Layer-wise Additive Manufacturing Predictions and Simulations (LAMPS ${ }^{\circledR}$ ) simulation parameters.

\begin{tabular}{cccccccc}
\hline Material & $\begin{array}{c}\text { Length } \\
(\mathbf{m m})\end{array}$ & $\begin{array}{c}\text { Width } \\
(\mathbf{m m})\end{array}$ & $\begin{array}{c}\text { Thickness } \\
(\mathbf{m m})\end{array}$ & $\begin{array}{c}\text { Thermal } \\
\text { Conductivity } \\
(\mathbf{W} / \mathbf{m}-\mathbf{K})\end{array}$ & $\begin{array}{c}\text { Density } \\
\left(\mathbf{g} / \mathbf{c m}^{\mathbf{3}}\right)\end{array}$ & $\begin{array}{c}\text { CTE }(\mathbf{1 0} \\
\left.\mathbf{K}^{-\mathbf{1}}\right)\end{array}$ & $\begin{array}{c}\text { Heat Capacity } \\
(\mathbf{J} / \mathbf{g}-\mathrm{K})\end{array}$ \\
\hline Ti-6Al-4V & 30 & 3 & 0.44 & 6.7 & 4.43 & 8.6 & 0.526 \\
BAlSi-4 & 3 & 3 & 0.1 & 205 & 2.66 & 21 & 0.9 \\
RMF & 3 & 3 & 0.135 & 76 & 4.91 & 12.5 & 0.536 \\
\hline
\end{tabular}

\subsection{Characterization}

Cross-sectional analysis was evaluated by embedding a lap joint sample in epoxy and then polishing with $\mathrm{SiC}$ paper, then diamond paste and, finally, colloidal silica particles. Scanning Electron Microscopy (SEM) images were collected on a Zeiss Auriga Scanning Electron Microscope (Zeiss, Oberkochen, Germany). X-ray diffraction measurements were conducted on a Panalytical Empyrean X-ray Diffractometer (Panalytical, Almelo, The Netherlands); the post-brazing XRD profile was obtained from the lap-joint cross-section embedded in epoxy the XRD beam line is perpendicular to the bond interface to detect all phases present in the joint. Lastly, Energy Dispersive X-ray Spectroscopy (EDX) measurements were performed using a Zeiss MA15 EVO SEM (Zeiss, Oberkochen, Germany) equipped with a Bruker $x$ Flash $6 \mid 30$ detector. A PowerView HS-650 highspeed camera (1500 frames/s) (DICKEY-john ${ }^{\circledR}$ Corporation, Auburn, IL, USA) was used to determine the reaction propagation speed of Ni/Al films. Differential scanning calorimetry (DSC) was performed using a Netzsch-Gerätebau STA 449 C Jupiter Thermo-microbalance (AZO materials, Manchester, UK).

\section{Results and Discussion}

\subsection{Characterization of RMF and BAl-Coated Ti64}

The total thickness achieved is $32.9 \mu \mathrm{m}$ with a bilayer thickness of $110 \mathrm{~nm}$ as seen in Figure 2a. The average Ni layer thickness (white) is $44 \mathrm{~nm}$ and the average Al layer thickness is $66 \mathrm{~nm}$, producing a $110 \mathrm{~nm}$ bilayer thickness (Figure 2b). The thickness ratio between $\mathrm{Al}$ and $\mathrm{Ni}$ was kept $1.5: 1$ to obtain an equiatomic ratio [15]. Equal $\mathrm{Al}$ and $\mathrm{Ni}$ layer thickness produces a $\mathrm{Ni}: \mathrm{Al}$ atomic ratio of 1.5:1, which proved unable to join BAlSi-4 via electrical ignition. The XRD pattern in Figure $3 a$ shows that $\mathrm{Ni}$ and $\mathrm{Al}$ were deposited with no significant intermixing between the as-deposited layers. 
The post-ignition XRD scan was performed on a free-standing film that was peeled off the polyimide substrate. The post-ignition XRD scan detects only AlNi, indicating complete reaction of the RMF. The total reaction heat is $1275 \mathrm{~J} / \mathrm{g}$ as shown by DSC (Figure 4). The reaction propagation speed is $4.36 \mathrm{~m} / \mathrm{s}$. As seen by the high-speed camera images (Figure 5), the RMF reaction completes very quickly ( $4.6 \mathrm{~ms})$, but the film cools down over 30 times longer $(169.5 \mathrm{~ms})$ as indicated by the diminishing light intensity. The $\mathrm{Ni} / \mathrm{Al}$ reaction is known as a solid + liquid reaction [16]. In the context of the $\mathrm{RMF}$ reaction, first the $\mathrm{Al}$ layers melt, then, the solid Ni layers dissolve in the molten $\mathrm{Al}$ and this is concluded by crystallization of Ni-Al intermetallic compounds. Melting and dissolution occurs during reaction propagation and crystallization occurs after the end of the propagation phase $[17,18]$.

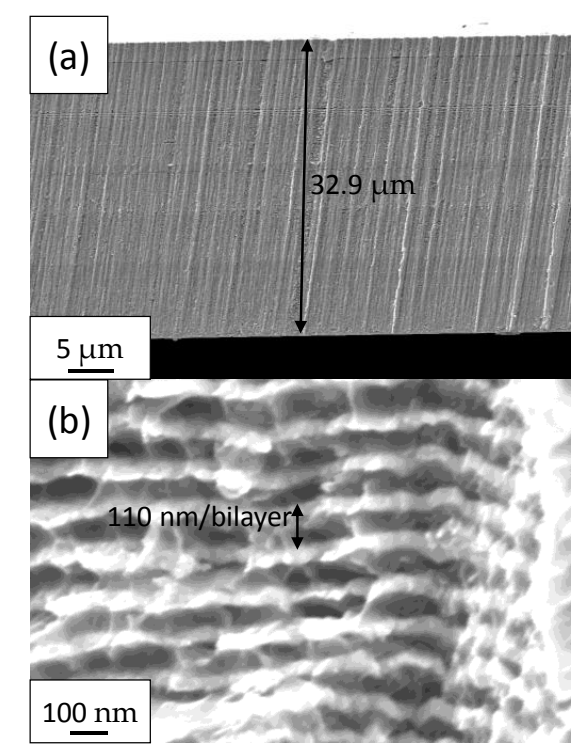

Figure 2. (a) SEM image showing the total as-fabricated RMF thickness and (b) the bilayer thickness (white is $\mathrm{Ni}$ and grey is $\mathrm{Al}$ ).

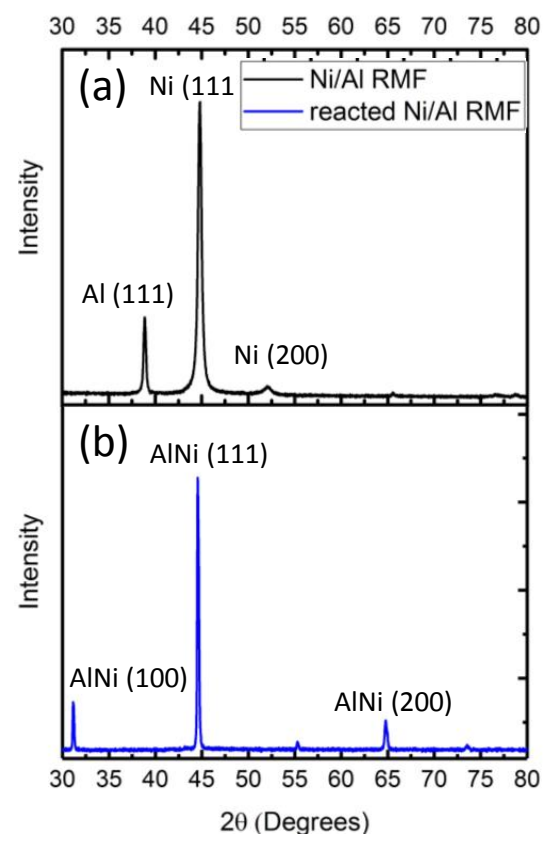

Figure 3. XRD pattern of the Ni/Al RMF (a) as-fabricated and (b) post ignition. 


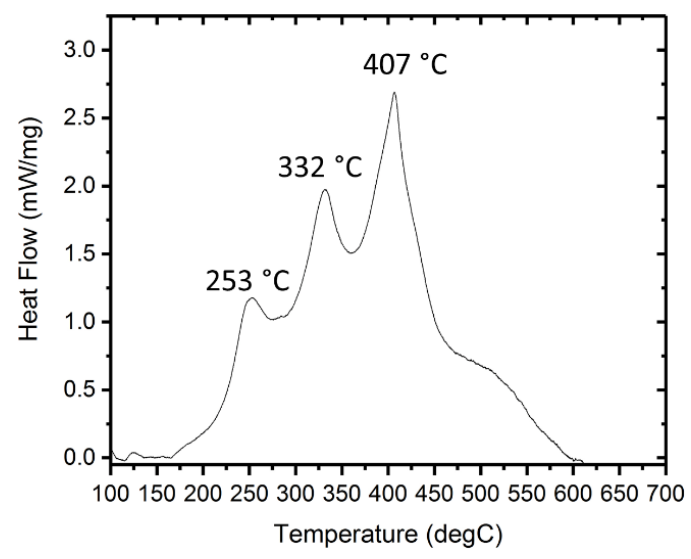

Figure 4. DSC measurement of Ni/Al RMFs.

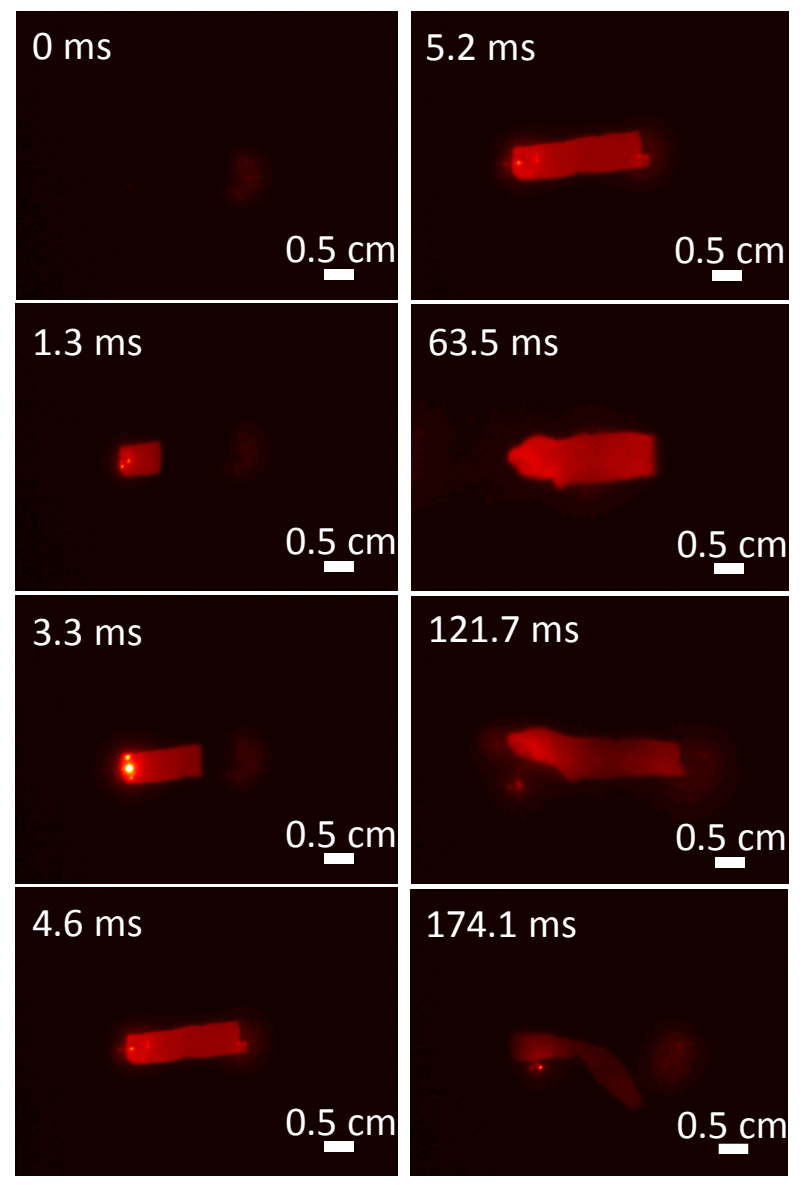

Figure 5. High speed camera measurement of the RMF reaction.

\subsection{Elemental Profiles and Temperature Evolution}

The EDS line scan of the cross-section reveals the general distribution of elements in the joint. The dips and spikes in the $\mathrm{Al}$ and $\mathrm{Si}$ in the region on both sides of the RMF is due to detection of Si-rich grains in an Al-rich matrix (Figure 6a,b). A high-resolution line scan of the Ti64-BAl interface reveals a reaction zone produced during the plasma-arc coating (Figure $6 c, d$ ). Additionally, there is an increased concentration of $\mathrm{Si}$ detected at the Ti64-BAl interface. Si has limited solubility in Ti in a solid state so, when $\mathrm{Si}$ attempts to diffuse into Ti from the molten brazing material, it stagnates at the Ti64 
surface. Notice that there is a reaction zone at the Ti64-BAl interface. EDS point analysis of this region reveals that this region is very Al-rich. Therefore, the formation of the reaction zone arises from $\mathrm{Ti}$ from the base material dissolving into the molten Al-Si and solidifying prior to the rest of the brazing material. Si is a melting point depressant so it is likely that the Al remained in its liquid state longer than normal, especially near the interface where the Si concentration was elevated [19]. If the $\mathrm{Al}$ is liquid for a longer time, it would allow more Ti to diffuse into the brazing material and expand the width of the reaction zone.
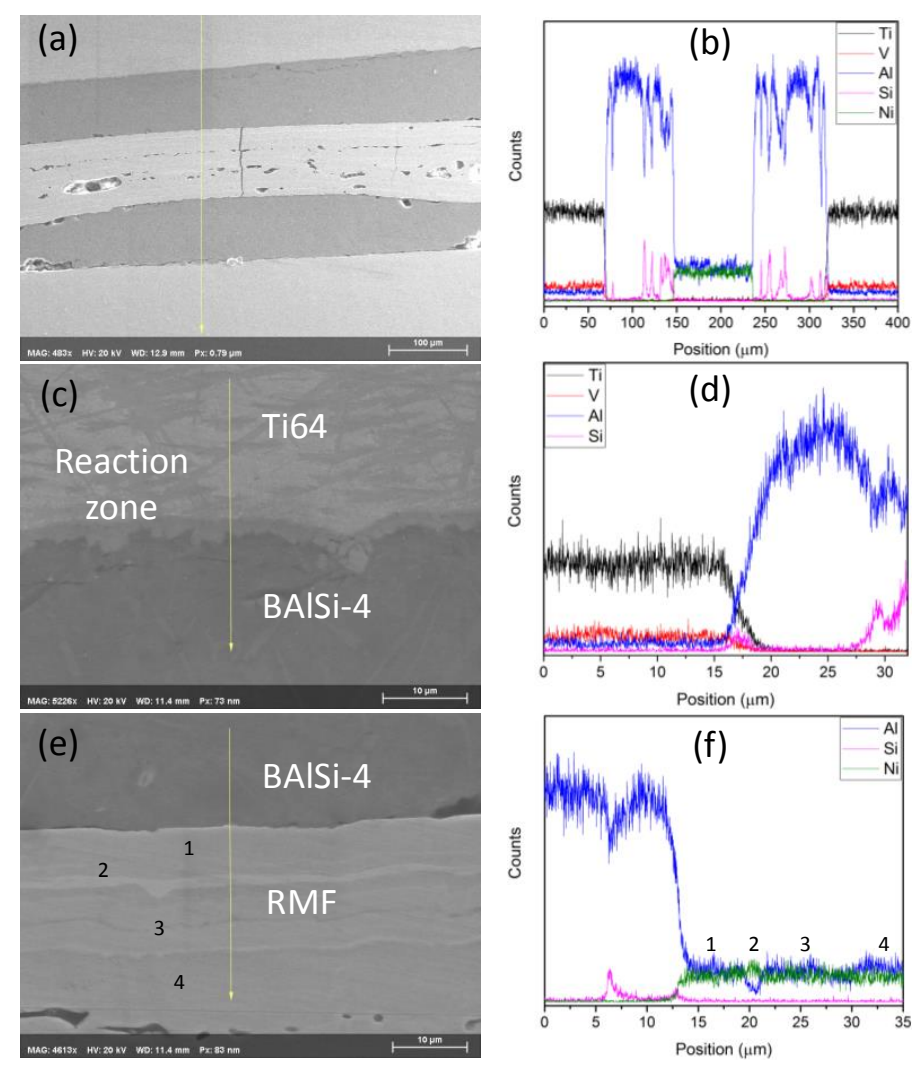

Figure 6. EDS line scan of $(\mathbf{a}, \mathbf{b})$ the entire brazed joint, $(\mathbf{c}, \mathbf{d})$ theTi64-BAl interface, and (e,f) BAl-RMF interface with select point analysis.

The RMF-BAl interface also yielded interesting results. As seen in Figure $6 \mathrm{e}, \mathrm{f}$ there are no obvious signs of a reaction zone, but there is a $1.6 \mu \mathrm{m}$ thick Ni-rich zone $6.4 \mu \mathrm{m}$ from the RMF-BAl interface. The diffusion length for $\mathrm{Al}$ is approximately $2.0 \mu \mathrm{m}$ and $\mathrm{Ni}$ is approximately $1.2 \mu \mathrm{m}$. No noticeable reaction zone forms for three primary reasons: (1) A lack of excess $\mathrm{Ni}$ (i.e., above the equiatomic amount), (2) short reaction time, and (3) the lower intrinsic diffusion coefficient of $\mathrm{Ni}$ compared to $\mathrm{Al}[20,21]$. During the reaction, virtually all the $\mathrm{Ni}$ is consumed in the RMF reaction and is largely unavailable for any significant reaction with the brazing material (i.e., not enough to produce a secondary phase in the reaction zone or on the interface). This is in direct contrast to a Ni-rich RMF (Ni:Al atomic ratio = 1.5:1), where the excess Ni reacted with the molten $\mathrm{Al}$ in the BAl and formed a dendrite structure. However, this non-equimolar RMF produces significantly weaker bonding (0.59 MPa) than the equimolar RMF in this current study [22]. EDS indicates near-equiatomic amounts of $\mathrm{Ni}$ and $\mathrm{Al}$ at points 1, 3, and 4 (indicated in Figure 6e), with slight $\mathrm{Al}$ enrichment at point 4 and slight $\mathrm{Ni}$ enrichment at point 3 . According to the Ni-Al phase diagram, these concentrations correspond to the AlNi phase. Point 2 detects almost two times the amount of $\mathrm{Ni}$ in this region compared to $\mathrm{Al}$, which is characteristic of the $\mathrm{Ni}_{5} \mathrm{Al}_{3}$ phase. $\mathrm{XRD}$ of the brazed joint (Figure 7) revealed several phases belonging to the parent structures, but the two particularly interesting peaks belong to 
$\mathrm{Al}_{3} \mathrm{Ti}$ and $\mathrm{Ni}_{5} \mathrm{Al}_{3}$, which, in conjunction with the EDS data, belong to the reaction zone at the Ti64-BAl interface and the Ni-rich region in the RMF, respectively. The $\mathrm{Al}_{3} \mathrm{Ti}$ phase was formed during the plasma coating process based on SEM observations prior to RMF brazing.

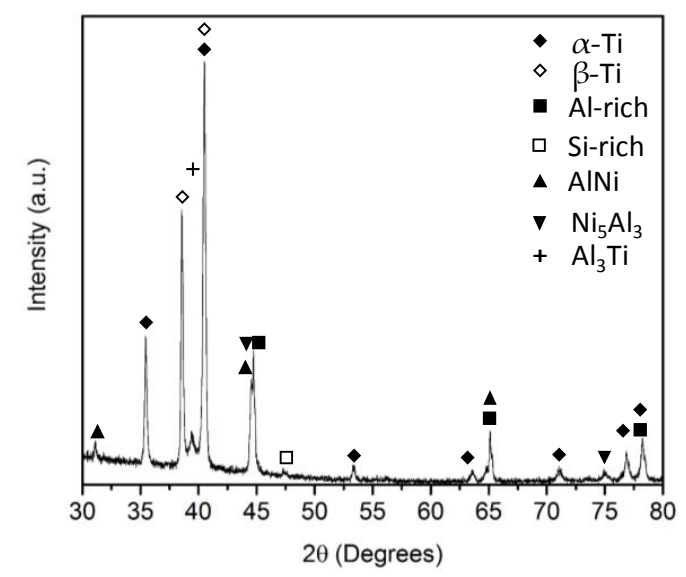

Figure 7. XRD pattern of the brazed joint.

The temperature evolution of the joint as a function of time helps in understanding the most probable pathway to the nucleation of the Ni-rich phase in the brazing joint. The temperature distribution of the brazing joint cross section, according to LAMPS, is shown in Figure 8. The BAl and RMF reach a maximum temperature of approximately $813^{\circ} \mathrm{C}$, which is far above the liquidus line of BAl. The LAMPS simulation shows that the temperature within the brazing region (i.e., the RMF and BAlSi-4) increases by $991^{\circ} \mathrm{C} / \mathrm{ms}$. The temperature decreases at a rate of $32.9^{\circ} \mathrm{C} / \mathrm{ms}$ in the center of the RMF, $38.8^{\circ} \mathrm{C} / \mathrm{ms}$ at the RMF-BAl interface, and $37.5^{\circ} \mathrm{C} / \mathrm{ms}$ at the Ti64-BAl interface, as shown in Figure 9. The faster heat dissipation at the interface is due to heat sinking in the $\mathrm{BAl}$ and Ti64.
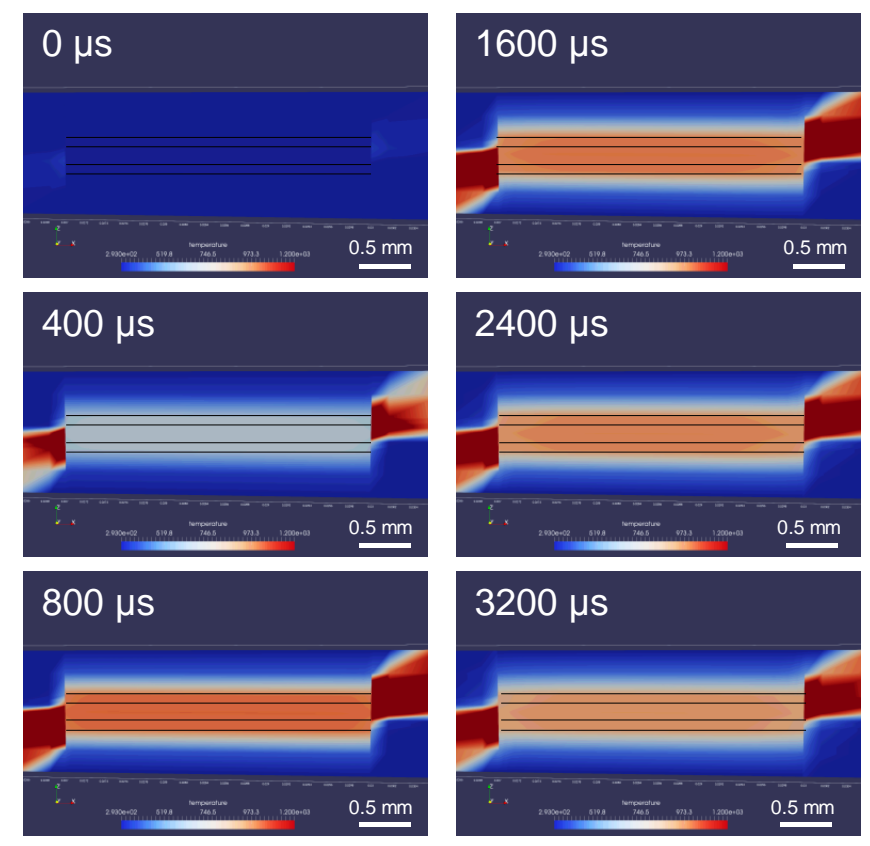

Figure 8. Snapshots of the LAMPS $^{\odot}$ simulation, showing the temperature evolution and distribution in the brazed joint at various time steps. 


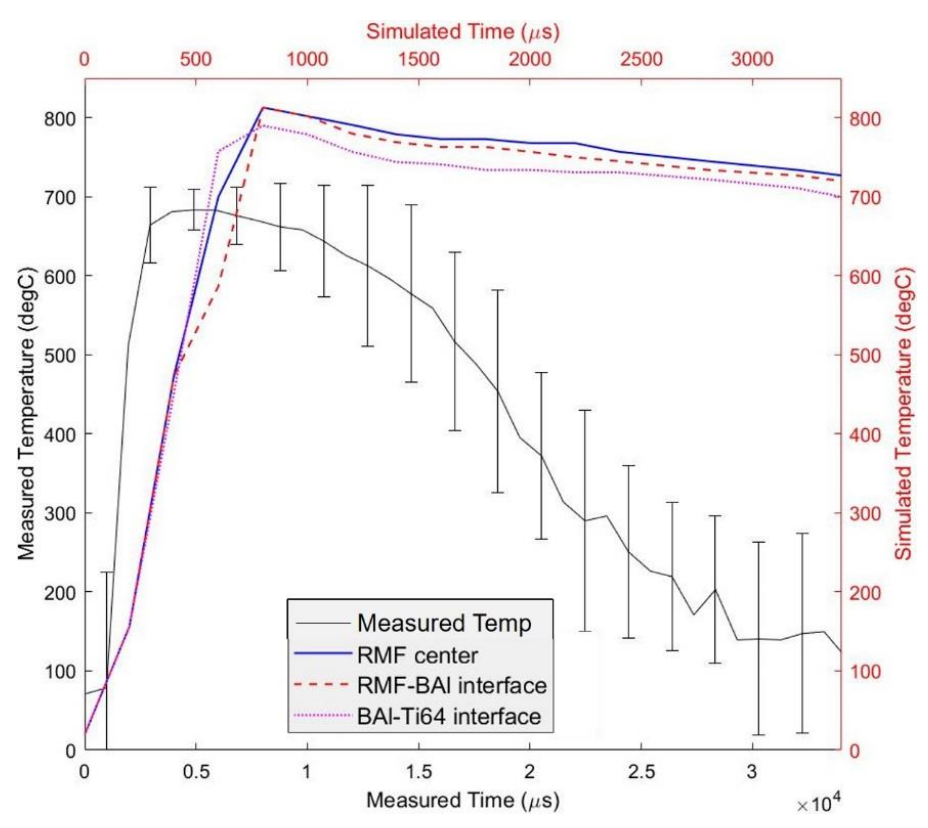

Figure 9. Temperature as a function of time simulated by LAMPS $^{\odot}$ (red, blue, and magenta lines) and measured using the highspeed camera (black solid line).

This simulation is further validated by the surface measurement of brazing materials with high speed imaging. The measurement indicates the maximum surface temperature reached is only $683^{\circ} \mathrm{C}$. The temperature increases by $125.5^{\circ} \mathrm{C} / \mathrm{ms}$ and decreases by $6.8-27.3^{\circ} \mathrm{C} / \mathrm{ms}$, depending on how much time has elapsed after the maximum temperature is reached. The measured temperature is significantly lower than the simulated temperature because the LAMPS $^{\odot}$ simulation is an idealized case of RMF brazing. For a real case, thermal conductivity and heat capacity are functions of temperature and, in the LAMPS simulation, it is assumed to be constant. Heat capacity increases with temperature for most materials, including $\mathrm{Al}$ [23-25], which means, as the temperature increases, more heat will be required to increase the temperature per degree Celsius. Convective heat loss is also not accounted for in the LAMPS $^{\odot}$ simulation. Convective heat loss and higher heat capacity and higher temperatures will, certainly, decrease the maximum temperature attained during the RMF reaction. Lastly, we assume, in the LAMPS ${ }^{\odot}$ simulation, that the RMF is defect free and perfectly flat. However, defects present in the real RMF [3], which are possibly introduced through applied pressure, can decrease the propagation efficiency of the film [26].

Based on the measured temperature, heating rate, and cooling rate and, assuming almost instantaneous melting, the BAl would be in the liquid state for approximately $10 \mathrm{~ms}$. Most of the interdiffusion occurs when the brazing material is in a molten state. When the brazing material and the RMF return to the solid state, diffusion slows down significantly. When the reaction occurs, Al diffuses into the RMF from the brazing material and Ni diffuses into the brazing material. Since the temperature cools at the interface first, the braze and the RMF will become completely solid at the interface first. As the temperature decreases throughout the joint, the solubility of $\mathrm{Ni}$ in $\mathrm{Al}$ rapidly declines. Due to the temperature gradient that exists in the joint cross-section, there is also a Ni diffusivity gradient. When the Ni diffusivity and solubility drop below some critical value, the Ni will continue to diffuse from the center of the RMF, but the diffusion and dissolution rate of $\mathrm{Ni}$ will quickly slow down close to the interface due to the lower temperature. When the portion of the RMF that is $6.4 \mu \mathrm{m}$ from the BAl-RMF interface has fully solidified, there is a build-up of Ni that has not diffused into the rest of the RMF layer or dissolved in the molten $\mathrm{Al}$ during the reaction propagation and, based on the Ni now present in this region, that portion of the RMF will crystallize into $\mathrm{Ni}_{5} \mathrm{Al}_{3}$. 


\subsection{Mechanical Properties}

The shear strength of the brazed joint was evaluated as a function of pressure and the RMF thickness. Applied pressure serves an important role in RMF brazing because it ensures intimate contact between the RMF and the brazing material [27]. However, excessive pressure will cause the molten brazing material to be squeezed out of the joint, which is why the bonding strength decreases above $20 \mathrm{MPa}$ applied pressure, as shown in Figure 10a. The RMF thickness was kept to $66 \mu \mathrm{m}$ for the pressure investigation. The maximum bonding strength $(10.6 \mathrm{MPa})$ was achieved using $20 \mathrm{MPa}$ applied pressure and RMF thickness $=165 \mu \mathrm{m}$. The effect of increasing the RMF thickness is, primarily, increasing the overall heat release, which increases the amount of molten liquid during brazing. The low bonding strength, despite the sufficient interface temperature, is attributed to the limited metallurgical bonding and low reaction time. These two causes are related by diffusion. Low diffusion is a result of a short reaction time and limited metallurgical bonding is partially caused by low interdiffusion. The fracture surfaces, shown in Figure 11, display some small cleavage fracture features. Several microcracks also appear in the surface as the RMF thickness increases. The appearance of microcracks and cleavage fracture features is partially due to the brittle nature of the $\mathrm{AlNi}$ and $\mathrm{Ni}_{5} \mathrm{Al}_{3}$ intermetallic compounds that comprise the RMF layer after brazing. Also, as previously stated, the low interdiffusion between the brazing and RMF layers ensures that the brazed joint fails primarily at the RMF-BAl interface due to a lack of strong metallurgical bonding. Additionally, the hardness map, shown in Figure 12, shows that there is almost no hardness gradient across the RMF-BAl interface, further indicating a lack of a reaction zone along that interface. Furthermore, the hardness is uniform within the RMF $(\sim 524 \mathrm{HV})$ and BAl $(\sim 75 \mathrm{HV})$ layers of the brazed joint. The Ti64-BAl interface, however, has a hardness gradient across the interface due to the presence of the $\mathrm{Al}_{3} \mathrm{Ti}$ at the interface.
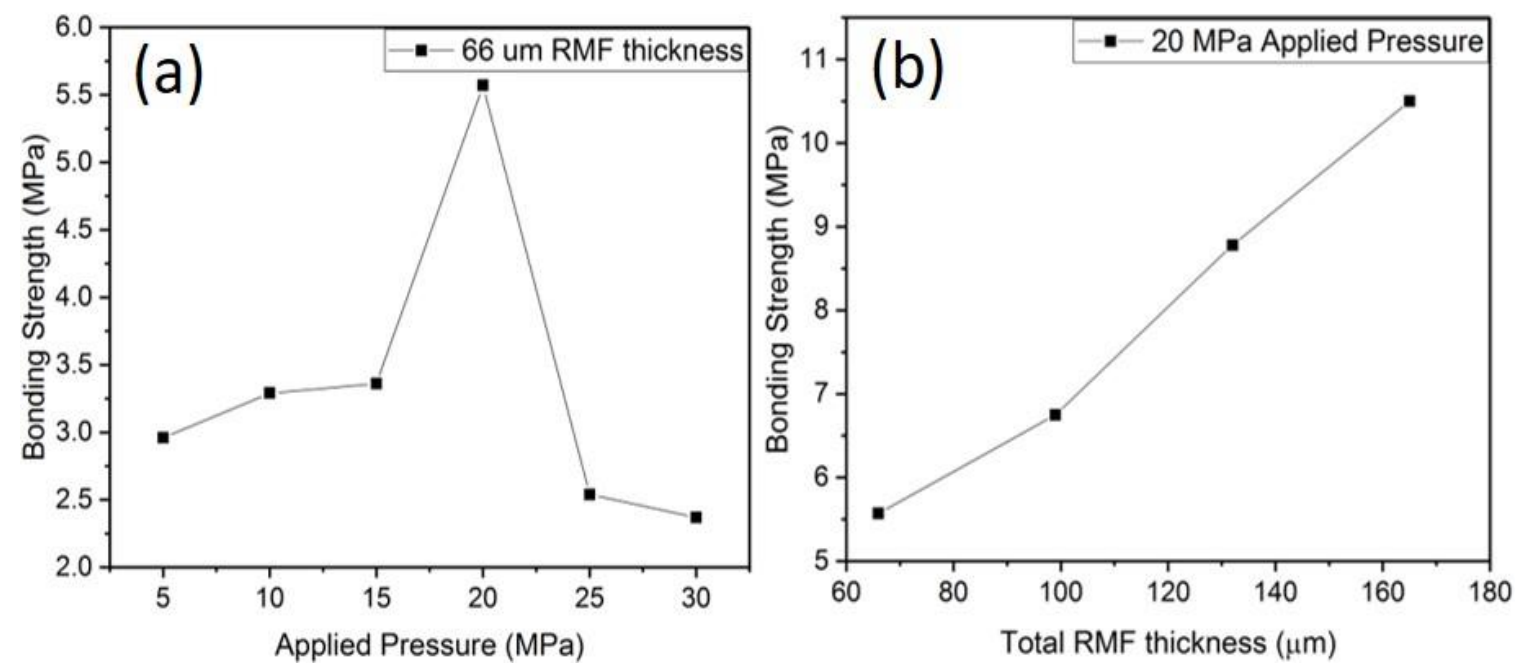

Figure 10. (a) Bonding strength as a function of applied pressure (RMF thickness kept constant at $66 \mu \mathrm{m})$. (b) Bonding strength as a function of total RMF thickness (Applied pressure $=20 \mathrm{MPa}$ ). 

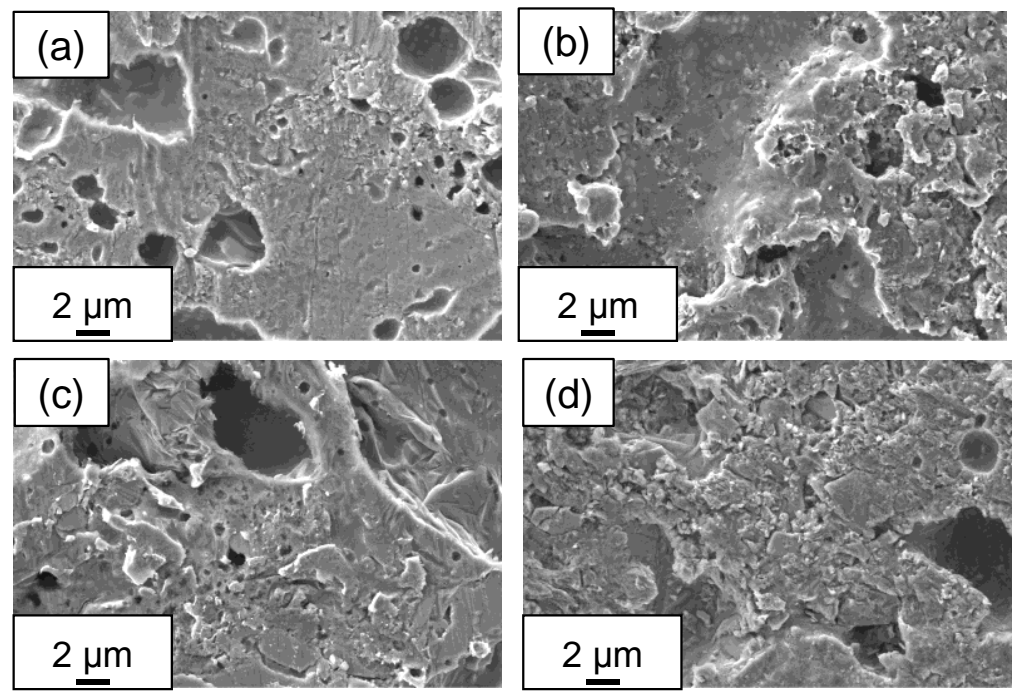

Figure 11. Fracture surfaces of RMF-brazed joints, with an RMF thickness of (a) $66 \mu \mathrm{m}$, (b) $99 \mu \mathrm{m}$, (c) $132 \mu \mathrm{m}$, and (d) $165 \mu \mathrm{m}$.

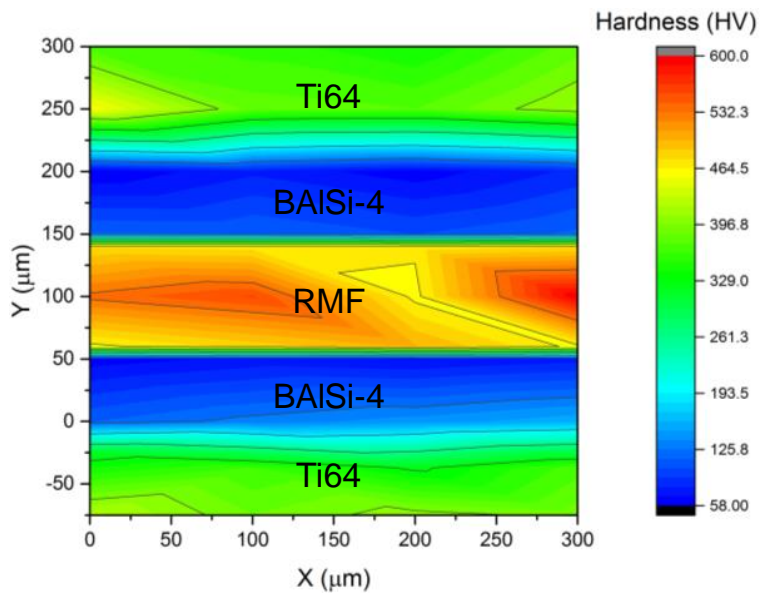

Figure 12. Hardness map of a $300 \mu \mathrm{m} \times 300 \mu \mathrm{m}$ section of the brazed joint.

\subsection{Future Work}

Currently, the bonding strength of the RMF makes it suitable for die attach applications [8]; however, for high strength applications, the bonding strength needs to be greatly improved. Future work on this technique should focus primarily on further improving the bonding strength of the RMF brazed joint. Improving the bonding strength can be accomplished by changing the RMF species to produce a more ductile RMF species. For example, Woll et al. investigated the ductility of Ru/Al RMFs and these proved to be much more ductile and energetic than Ni/Al RMFs [28]. The bonding performance of $\mathrm{Ru} / \mathrm{Al}$ RMFs has not been studied yet and the high cost of Ru limits the possibilities for a feasible joining study.

The current low bonding strength can be attributed to the limited diffusion during the very short reaction. This has been evident in pressure-assisted diffusion bonding at high temperatures [11]. So, an alternative solution is to strengthen the bonding through the direct contact of brazing materials. $\mathrm{Ni} / \mathrm{Al}$ RMFs could be embedded within a trenched BAlSi-4 brazing layer (Figure 13). When the RMF is ignited, the reaction heat will result in an RMF-BAl interface like the ones described in this study. Additionally, the reaction heat will melt the corners of the BAlSi-4 (indicated by arrows in Figure 13) and will fuse to the opposing BAISi-4 surface. Ideally the union of two BAISi-4 surfaces will be much 
stronger than the union of Ni/Al RMF and BAlSi-4. The AlNi intermetallic compound will serve as a strengthening precipitate instead of the primary load-bearing layer. For a large brazing area, multiple ignition points can be used to ensure that the reaction is not quenched before completion. Lastly, characterization of the thermomechanical properties of the RMF-brazed joint will also need to be conducted.

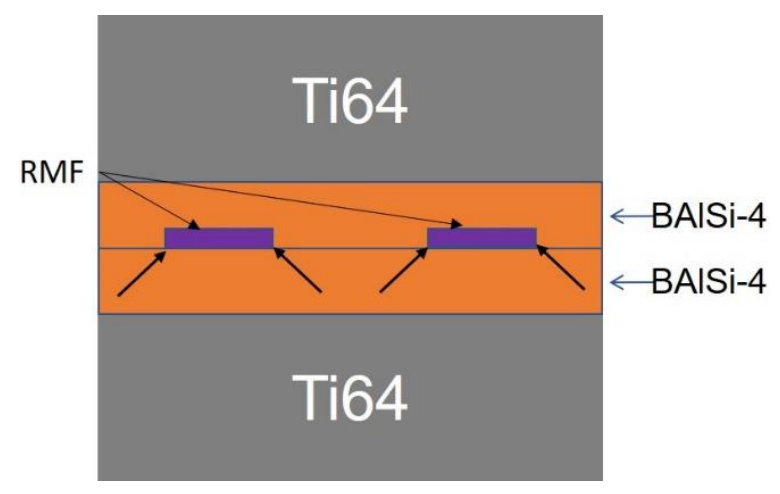

Figure 13. Suggested "embedded RMF joining" schematic; arrows indicate where the adjacent BAlSi-4 surfaces would fuse together.

\section{Conclusions}

Self-powered brazing using Ni/Al RMFs has been demonstrated for quick brazing BAl-coated Ti64 without using a long brazing procedure, such as furnace brazing. The total heating and cooling time was less than 100 milliseconds. Due to a difference in the diffusivity of $\mathrm{Ni}$ and $\mathrm{Al}, \mathrm{Ni5} \mathrm{Al} 3$ nucleated in the RMF, in addition to the AlNi phase. However, no apparent reaction zone formed at the RMF-BAl interface due to a lack of excess $\mathrm{Ni}$ and the extremely short brazing time. The Ti64-BAl interface, on the other hand, clearly had a reaction zone in which Al3Ti was present. Applied pressure needs to be controlled to optimize bonding performance and there was a positive correlation between bonding strength and RMF thickness. Due to the local heating, the total operation can be completed within $1 \mathrm{~min}$. This significantly simplifies the brazing technique.

Supplementary Materials: The following are available online at http://www.mdpi.com/2076-3417/8/6/985/s1, Video: cross-section view.avi.

Author Contributions: Conceptualization, D.B. and A.H.; Funding acquisition, Y.B.-C. and A.H.; Investigation, D.B., C.S., K.H. and J.C.; Methodology, D.B., C.R., Z.G., Z.Z. and K.H.; Software, C.S. and J.C.; Supervision, Y.B.-C. and A.H.; Validation, D.B.; Visualization, J.C.; Writing-original draft, D.B.; Writing-review \& editing, A.H.

Funding: This project is jointly supported by a subcontract with the Jet Propulsion Laboratory/California Institute of Technology, the National Aeronautics and Space Administration (NASA) and a Department of Energy (DOE) Office of Science User Facility project at the Center for Nanophase Materials, Oak Ridge National Laboratory.

Acknowledgments: We also acknowledge John Dunlap, Maulik Patel, and the Joint Institute of Advanced Materials for use of their electron microscopy, EDX, and X-ray diffraction equipment and the training they provided.

Conflicts of Interest: The authors declare no conflict of interest.

\section{References}

1. Bar-Cohen, Y.; Olorunsola, A.K.; Badescu, M.; Bao, X.; Sherrit, S. Simultaneous sealing and external surface sterilization of containers with samples. NASA Tech. Briefs 2008, 32, 38-40.

2. Sen, S.; Lake, M.; Wilden, J.; Schaaf, P. Synthesis and characterization of ti/al reactive multilayer films with various molar ratios. Thin Solid Films 2017, 631, 99-105. [CrossRef]

3. Adams, D.P. Reactive multilayers fabricated by vapor deposition: A critical review. Thin Solid Films 2015, 576, 98-128. [CrossRef] 
4. Simoes, S.; Ramos, A.S.; Viana, F.; Vieira, M.T.; Vieira, M.F. Joining of tial to steel by diffusion bonding with $\mathrm{Ni} / \mathrm{Ti}$ reactive multilayers. Metals 2016, 6, 96. [CrossRef]

5. Longtin, R.; Hack, E.; Neuenschwander, J.; Rusch, J. Benign joining of ultrafine grained aerospace aluminum alloys using nanotechnology. Adv. Mater. 2011, 23, 5812-5816. [CrossRef] [PubMed]

6. Qiu, X.; Wang, J. Bonding silicon wafers with reactive multilayer foils. Sens. Actuators A Phys. 2008, 141, 476-481. [CrossRef]

7. Ma, Y.; Li, H.; Bridges, D.; Peng, P.; Lawrie, B.; Feng, Z.; Hu, A. Zero-dimensional to three-dimensional nanojoining: Current status and potential applications. RSC Adv. 2016, 6, 75916-75936. [CrossRef]

8. Gunduz, I.E.; Kyriakou, A.; Vlachos, N.; Kyratsi, T.; Doumanidis, C.C.; Son, S.; Rebholz, C. Spark ignitable ni-al ball-milled powders for bonding applications. Surf. Coat. Technol. 2014, 260, 396-400. [CrossRef]

9. Swiston, A.J.; Hufnagel, T.C.; Weihs, T.P. Joining bulk metallic glass using reactive multilayer foils. Scr. Mater. 2003, 48, 1575-1580. [CrossRef]

10. Hooper, R.J.; Adams, D.P.; Hirschfeld, D.; Manuel, M.V. The effect of substrate microstructure on the heat-affected zone size in sn-zn alloys due to adjoining $\mathrm{Ni}$-Al reactive multilayer foil reaction. J. Electron. Mater. 2016, 45, 1-11. [CrossRef]

11. Ma, Y.; Li, H.; Yang, L.; Hu, A. Reaction-assisted diffusion bonding of ti6al4v alloys with Ti/Ni nanostructured multilayers. J. Mater. Process. Technol. 2018. [CrossRef]

12. Resnik, D.; Vrtačnik, D.; Aljančič, U.; Mozek, M.; Peni, S.; Amon, S. Influence of mechanical stress on adhesion properties of DC magnetron sputtered $\mathrm{Ti} / \mathrm{NiV} / \mathrm{Ag}$ layers on $\mathrm{N}^{+} \mathrm{Si}$ substrate. Microelectron. Eng. 2008, 85, 1603-1607. [CrossRef]

13. Weihs, T.P. Fabrication and characterization of reactive multilayer films and foils. In Metallic Films for Electronic, Optical and Magnetic Applications: Structure, Processing and Properties; Woodhead Publishing Limited: Philadelphia, PA, USA, 2014; pp. 160-243.

14. Fritz, G.M.; Spey, S.J., Jr.; Grapes, M.D.; Weihs, T.P. Thresholds for igniting exothermic reactions in al/ni multilayers using pulses of electrical, mechanical, and thermal energy. J. Appl. Phys. 2013, 113, 14901. [CrossRef]

15. Xu, R.G.; Falk, M.L.; Weihs, T.P. Interdiffusion of ni-al multilayers: A continuum and molecular dynamics study. J. Appl. Phys. 2013, 114, 163511. [CrossRef]

16. Miura, S.; Ohashi, T.; Mishima, Y. Amount of liquid phase during reaction synthesis of nickel aluminides. Intermetallics 1997, 5, 45-59. [CrossRef]

17. Turlo, V.; Politano, O.; Baras, F. Alloying propagation in nanometric Ni/Al multilayers: A molecular dynamics study. J. Appl. Phys. 2017, 121, 055304. [CrossRef]

18. Rogachev, A.S.; Vadchenko, S.G.; Baras, F.; Politano, O.; Rouvimov, S.; Sachkova, N.V.; Mukasyan, A.S. Structure evolution and reaction mechanism in the Ni/Al reactive multilayer nanofoils. Acta Mater. 2014, 66, 86-96. [CrossRef]

19. Hdz-García, H.M.; Martinez, A.I.; Muñoz-Arroyo, R.; Acevedo-Dávila, J.L.; García-Vázquez, F.; Reyes-Valdes, F.A. Effects of silicon nanoparticles on the transient liquid phase bonding of 304 stainless steel. J. Mater. Sci. Technol. 2014, 30, 259-262. [CrossRef]

20. Fujiwara, K.; Horita, Z. Measurement of intrinsic diffusion coefficients of al and Ni in ni3al using ni/nial diffusion couples. Acta Mater. 2002, 50, 1571-1579. [CrossRef]

21. Janssen, M.M.P. Diffusion in the nickel-rich part of the $\mathrm{Ni}-\mathrm{Al}$ system at $1000^{\circ}$ to $1300{ }^{\circ} \mathrm{C}$; Ni3Al layer growth, diffusion coefficients, and interface concentrations. Metall. Trans. 1973, 4, 1623-1633.

22. Bridges, D.; Rouleau, C.; Gosser, Z.; Hong, K.; Cheng, J.; Zhang, Z.; Smith, C.; Bar-Cohen, Y.; Hu, A. Prepartation of thick $\mathrm{Ni} / \mathrm{Al}$ reactive multilayer films and prospective use for self-powered brazing of Ti-6Al-4V. In Proceedings of the International Manufacturing Science and Engineering Conference, College Station, TX, USA, 18-22 June 2018; ASME: College Station, TX, USA, 2018.

23. Pochapsky, T.E. Heat capacity and resistance measurements for aluminum and lead wires. Acta Metall. 1953, 1, 747-751. [CrossRef]

24. Buyco, E.H.; Davis, F.E. Specific heat of aluminum from zero to its melting temperature and beyond. Equation for representation of the specific heat of solids. J. Chem. Eng. Data 1970, 15, 518-523. [CrossRef]

25. Chase, M.W. NIST-JANAF Themochemical Tables, 4th ed.; Journal of Physical Chemistry Reference Data; American Institute of Physics for the National Institute of Standards and Technology: Washington, DC, USA, 1998. 
26. Bartsch, H.; Manuel, J.M.; Grieseler, R. Influence of nanoscaled surface modification on the reaction of $\mathrm{Al} / \mathrm{Ni}$ multilayers. Technologies 2017, 5, 79. [CrossRef]

27. Wang, J.; Besnoin, E.; Knio, O.M.; Weihs, T.P. Investigating the effect of applied pressure on reactive multilayer foil joining. Acta Mater. 2004, 52, 5265-5274. [CrossRef]

28. Woll, K.; Bergamaschi, A.; Avchachov, K.; Djurabekova, F.; Gier, S.; Pauly, C.; Leibenguth, P.; Wagner, C.; Nordlund, K.; Mucklich, F. Ru/Al multilayers integrate maximum energy density and ductility for reactive materials. Sci. Rep. 2016, 6, 19535. [CrossRef] [PubMed]

(C) 2018 by the authors. Licensee MDPI, Basel, Switzerland. This article is an open access article distributed under the terms and conditions of the Creative Commons Attribution (CC BY) license (http://creativecommons.org/licenses/by/4.0/). 